\title{
STUDI KOMPARATIF TENTANG FERTILITAS MIGRAN DAN NONMIGRAN DI KOTA SINGARAJA
}

\author{
Maria Adelia Suryani Haribaik, Ida bagus Made Astawa, Sutarjo \\ Jurusan Pendidikan Geografi \\ Universitas Pendidikan Ganesha \\ Singaraja, Indonesia \\ e-mail: adeharibaik@gmail.com , idabagusmadeastawa@yahoo.com , \\ sutarjo@gmail.com
}

\begin{abstract}
Abstrak
Penelitian ini dilaksanakan di Kota Singaraja dengan tujuan: (1). mengidentifikasi karakteristik fertilitas migran dan nonmigran di Kota Singaraja. (2). menganalisis faktor-faktor yang mempengaruhi fertilitas migran dan nonmigran di Kota Singaraja. (3). menganalisis perbedaan fertilitas migran dan nonmigran di Kota Singaraja. Penelitian ini dirancang sebagai penelitian deskriptif dengan sampel sebesar $10 \%$ dari populasi sebesar 626 migran dan 624 nonmigran (62 migran dan 61 nonmigran) yang diambil secara Proportional Random Sampling. Pengumpulan data primer menggunakan metode wawancara, dan sekunder menggunakan pencatatan dokumen, yang selanjutnya dianalisis dengan metode deskriptif kualitatif dan kuantitatif.

Hasil penelitian menunjukkan bahwa (1). migran memiliki anak rata-rata antara 3-4 anak sedangkan jumlah anak yang dimiliki oleh nonmigran rata-rata antara 1-2, dengan jarak kelahiran dengan pola yang berbeda. Pada migran jarak kelahiran anak yang dimiliki tidak teratur, namun pada nonmigran sudah lebih teratur antara 4,5,dan 6 tahun. (2). Faktor usia kawin pertama, pendapatan dan pendidikan tidak mempengaruhi perbedaan fertilitas migran dan nonmigran di Kota Singaraja. (3). Terdapat perbedaan fertilitas antara migran dan nonmigran di Kota Singaraja secara signifikan (t hitung 4,236 >t tabel 1,970, sig $0,05 \%)$
\end{abstract}

Kata kunci: Fertilitas, Migran, Nonmigran, Penduduk Wanita

\begin{abstract}
This research was conducted in Kota Singaraja with the aim of: (1). Identifying the characteristics of migrant and non-migrant fertility in Singaraja City. (2). Analyze the factors affecting the fertility of migrants and non-migrants in Singaraja Town. (3). Analyze the difference of migrant and non-migrant fertility in Singaraja Town. This study was designed as a descriptive study with a sample of $10 \%$ of the population of 626 migrants and 624 nonmigrants (62 migrants and 61 nonmigrants) taken by Proportional Random Sampling. Primary data collection using interview method, and secondary using document recording, which then analyzed by qualitative and quantitative descriptive method.
\end{abstract}


The results showed that (1). Migrants have children on average between 3-4 children while the number of children owned by nonmigrants averages between 1-2, with birth spacings with different patterns. In migrants the birth distance of children is not regular, but in nonmigrants have been more regularly between 4.5, and 6 years. (2). The first mating age factor, income and education did not affect the fertility and non-migrant fertility differences in Singaraja City. (3). There is a significant difference of fertility between migrants and nonmigrants in Singaraja City (t count 4,236>t table 1,970 sig 0,05\%)

Keywords: Fertility, Migrant, Nonmigrant, Female Population

\section{PENDAHULUAN}

Fertilitas merupakan salah satu variabel demografi yang berimplikasi pada bertambahnya jumlah penduduk di suatu daerah. Fertilitas dapat diartikan sebagai kemampuan nyata seorang wanita atau sekelompok wanita untuk melahirkan, yang dicerminkan dalam jumlah bayi yang pernah dilahirkan hidup (Sudjinggo, 1988:99).

Fertilitas menjadi sangat penting untuk diketahui, terutama dalam kaitannya dengan pemenuhan kebutuhan penduduk, baik yang bersifat sosial, ekonomi, dan politik. Dari segi sosial berkaitan tentang jumlah anak yang akan disekolahkan, dari segi ekonomi pemenuhan kebutuhan anak yang dilahirkan (sandang, pangan, dan papan) yang layak. Sementara dari segi politik akan terlihat saat anak sudah beranjak dewasa (mulai dari usia 17 tahun) yang akan berpartisipasi untuk menggunakan hak-hak politiknya, seperti dalam pemilihan umum baik sebagai calon maupun pemilih. Ketiga aspek ini sangat berkaitan dengan fertilitas.

Perilaku fertilitas penduduk antara desa dan kota pada umumnya berbeda. Fertilitas penduduk di kota lebih kecil dari pada di desa. Namun demikian, kota sebagai tujuan migrasi, fertilitasnya akan dipengaruhi oleh migran masuk. Migran yang masuk ke kota pada umumnya berasal dari desa. Perilaku fertilitas migran masuk ini pada umumnya masih bersifat fertilitas desa. Penduduk yang menjadi migran masuk ini, umumnya masih minim pengetahuannya tentang KB dan masih memerlukan adaptasi dengan perilaku fertilitas di kota.
Singaraja yang merupakan kota terbesar kedua di Bali setelah Kota Denpasar tidak terlepas juga dari adanya migran masuk. Sudibia (2013) dalam penelitiannya yang dipublikasikan melalui jurnal menjelaskan migran masuk ke kota pada umumnya berasal dari desa, kecenderungan migran masuk masih membawa pola fertilitas sesuai dengan tempat asal mereka. Fertilitas nonmigran pada umumnya rendah jika dibandingkan dengan migran. hal ini disebabkan oleh adanya respon positif terhadap berbagai program penurunan fertlitas (Rahmadewi, 2011). Di daerah perkotaan tingkat pelayanan KB yang disediakan tergolong baik, sehingga Wanita PUS nonmigran dapat berpartisipasi aktif dalam menggunakan KB. Selain itu, tingkat pendidikan yang baik juga mempengaruhi penggunaan alat kontrasepsi terhadap penduduk nonmigran (Rahmadewi, 2011).

Sebgaimananya halnya kotakota lain di Indonesia, migran yang masuk ke Kota Singaraja pada umumnya juga berasal dari desa, baik itu desa yang berada di dalam wilayah Provinsi Bali maupun dari luar wilayah Provinsi Bali. Perilaku migran masuk ke Kota Singaraja dapat meningkatkan fertilitas, sehingga berpengaruh terhadap dinamika fertilitas di Kota Singaraja.

Berkembangnya Kota

Singaraja tentu memberikan pilihan bagi calon migran untuk menjadikannya sebagai daerah tujuan bermigrasi. Selain itu berkembangnya Kota Singaraja sebagai kota pendidikan dengan adanya Undiksha 
sebagai perguruan tinggi negeri, juga dinilai akan menambah daya tariknya sebagai daerah tujuan bermigrasi. Jika dilihat dari dominannya para migran yang datang ke kota adalah berasal dari desa, tentu perilaku fertilitasnya juga akan dibawa ke kota tempat tujuannya bermigran. Jika hal ini terjadi maka ada kecenderungan fertilitas Kota Singaraja akan mengalami peningkatan.

Fertilitas yang terjadi di Kota Singaraja tergolong kecil, peningkatan jumlah penduduk yang terjadi lebih didominasi oleh banyaknya migran yang masuk. Kenyataan ini tentu juga akan berdampak pada fertilitas di Kota Singraja, karena fertilitas para migran masih menganut pola yang ada di daerah asalnya. Migran yang masuk tersebut bervariasi asalnya, baik dari dalam wilayah Provinsi Bali maupun dari luar wilayah Provinsi Bali.

Peningkatan fertilitas yang terjadi tentu akan berdampak pada semakin besarnya angka beban ketergantungan. Jika hal ini terjadi, biaya untuk penduduk yang belum produktif ( $<15$ tahun) akan bertambah, sehingga kesejahteraan keluarga akan menurun. Biaya- biaya yang semestinya dapat diperuntukkan bagi usaha produktif (pendidikan, kesehatan, industri, dan sebagainya) tidak dapat dilakukan sepenuhnya karena harus menanggung penduduk yang belum produktif (penduduk usia muda).

Berbagai penelitian telah dilakukan oleh sejumlah kalangan namun pada umumnya belum sampai pada memilah fertilitas migran dan nonmigran. Penelitian ini akan difokuskan pada karakteristik variasi tingkat fertilitas serta faktor-faktor yang mempengaruhi fertilitas migran dan nonmigran di Kota Singaraja, serta perbedaan fertilitas migran dan nonmigran.

Permasalahan pada penelitian ini (1) Bagaimanakah karakteristik fertilitas migran dan nonmigran di Kota Singaraja, (2) Faktor-faktor apa sajakah yang mempengaruhi fertilitas migran dan nonmigran di Kota Singaraja, (3) Apakah terdapat perbedaan tingkat fertilitas migran dan nonmigran di Kota Singaraja,

Tujuan dari penelitian (1) Mengidentifikasi karakteristik fertilitas migran dan nonmigran di Kota Singaraja. (2) Menganalisis faktorfaktor yang mempengaruhi fertilitas migran dan nonmigran di Kota Singaraja. (3) Menganalisis perbedaan tingkat fertilitas migran dan nonmigran di Kota Singaraja.

\section{METODE}

Penelitian ini dilakukan di Kota Singaraja. Objek dalam penelitian ini fertilitas migran dan nonmigran. Memperhatikan Objek Penelitian tersebut, yang menjadi subjek dalam penelitian ini adalah Pasangan Usia Subur (PUS) migran dan nonmigran di Kota Singaraja. Penelitian ini menggunakan racangan penelitian deskriptif. Data yang digunakan adalah data primer dan sekunder. Data sekunder bersumber dari Badan Pusat statistik Kabupaten Buleleng. Data primer yang telah dikumpulkan selanjutnya akan dianalisis menggunakan analisis deskriptif kualitatif dan kuantitatif dengan menggunakan pendekatan keruangan. Perbedaan fertilitas migran dan nonmigran di Kota Singaraja dianalisis menggunakan uji-t atau t-test dengan sampel bebas.

\section{HASIL DAN PEMBAHASAN}

\section{Jumlah Anak}

Tabel 2. Karakteristik vertilitas Pasangan Usia Subur (PUS) Migran dan Nonmigran Menurut Jumlah Anak

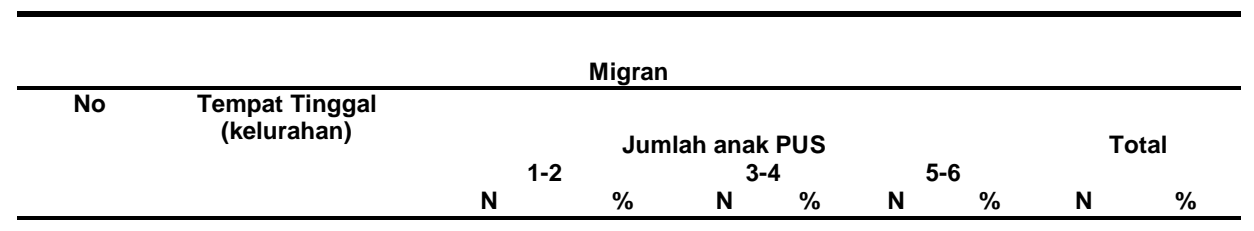




\begin{tabular}{|c|c|c|c|c|c|c|c|c|c|}
\hline 1 & Banyuasri & 7 & 58 & 3 & 25 & 2 & 17 & 12 & 100 \\
\hline 2 & Kampung Anyar & 3 & 27 & 6 & 55 & 2 & 18 & 11 & 100 \\
\hline 3 & Kampung Baru & 4 & 33 & 5 & 42 & 3 & 25 & 12 & 100 \\
\hline 4 & Penarukan & 2 & 18 & 6 & 55 & 3 & 27 & 11 & 100 \\
\hline 5 & Banyuning & 4 & 25 & 8 & 50 & 4 & 25 & 16 & 100 \\
\hline & Jumlah & 20 & 32 & 28 & 45 & 14 & 23 & 62 & 100 \\
\hline \multicolumn{10}{|c|}{ Nonmigran } \\
\hline 1 & Banyuasri & 6 & 60 & 4 & 40 & 0 & 0 & 10 & 100 \\
\hline 2 & Kampung Anyar & 9 & 69 & 4 & 31 & 0 & 0 & 13 & 100 \\
\hline 3 & Kampung Baru & 8 & 62 & 5 & 38 & 0 & 0 & 13 & 100 \\
\hline 4 & Penarukan & 7 & 70 & 3 & 30 & 0 & 0 & 10 & 100 \\
\hline \multirow[t]{2}{*}{5} & Banyuning & 5 & 33 & 10 & 67 & 0 & 0 & 15 & 100 \\
\hline & Jumlah & 35 & 57 & 26 & 43 & 0 & 0 & 61 & 100 \\
\hline
\end{tabular}

Sumber: Data Primer, 2017

Berdasarkan Tabel 2 terlihat jumlah anak yang dimiliki oleh PUS migran dan nonmigran berbeda. Jumlah anak untuk PUS migran didominasi di jumlah anak 3-4, tertinggi terdapat pada Kelurahan Kampung Anyar dan Penarukan (55\%) dan terendah terdapat pada Kelurahan Banyuasri (25\%). Sedangakan pada PUS nonmigran didominasi pada jumlah anak 1-2, tertinggi terdapat pada Kelurahan Penarukan $(70 \%)$ dan terendah terdapat pada Kelurahan Banyuning (33\%). Kesadaran ber-KB dari PUS migran masih tergolong rendah. Hal ini dibuktikan dengan masih adanya PUS dengan jumlah anak dikisaran 5 sampai 6 orang. Sementara untuk PUS nonmigran kesadaran ber-KB sudah tinggi. Hal tersebut dapat dilihat dari tidak adanya PUS dengan jumlah anak dikisaran 5 sampai 6 orang.

Dibandingkan dengan penelitian sebelumnya, penelitian ini memiliki persamaan dengan penelitian yang dilakukan oleh I Ketut Sudibia pada tahun 2013. Hasil penelitian menunjukan bahwa jumlah kelahiran anak berdasarkan paripurna kelompok migran lebih tinggi dibandingkan dengan wanita nonmigran.

Lebih besarnya jumlah anak penduduk migran dibandingkan dengan penduduk nonmigran dapat disebabkan oleh keinginan untuk memiliki anak dengan jenis kelamin tertentu serta tidak membuat rencana tertentu dalam menentukkan jumlah anak yang akan dimiliki. Kurangnya partisipasi dalam penggunaan KB menjadi salah satu alasan bagi wanita migran yang memiliki anak dengan jumlah yang banyak. Sementara wanita PUS nonmigran sudah lebih sadar akan pentingnya ber-KB untuk keberlangsungan hidup berkeluarga.

\section{Jarak Kelahiran antar Anak}

Tabel 3. Karakteristik Fertilitas Pasangan Usia Subur (PUS) Migran dan Nonmigran Menurut Jarak Kelahiran Anak di Kota Singaraja

\begin{tabular}{|c|c|c|c|c|c|c|c|c|c|c|c|}
\hline \multicolumn{12}{|c|}{ Migran } \\
\hline \multirow[t]{3}{*}{ No } & Tempat Tinggal & \multicolumn{8}{|c|}{ Jarak kelahiran anak PUS } & \multicolumn{2}{|c|}{ Total } \\
\hline & (Kelurahan) & \multicolumn{2}{|c|}{ A } & \multicolumn{2}{|c|}{ B } & \multicolumn{2}{|c|}{ C } & \multicolumn{2}{|c|}{ D } & & \\
\hline & & $\mathbf{N}$ & $\%$ & $\mathbf{N}$ & $\%$ & $\mathbf{N}$ & $\%$ & $\mathbf{N}$ & $\%$ & $\mathbf{N}$ & $\%$ \\
\hline 1 & Banyuasri & 0 & 0 & 1 & 11 & 1 & 11 & 7 & 78 & 9 & 100 \\
\hline 2 & Kampung Anyar & 1 & 11 & 1 & 11 & 1 & 11 & 6 & 67 & 9 & 100 \\
\hline 3 & Kampung Baru & 0 & 0 & 2 & 18 & 0 & 0 & 9 & 81 & 11 & 100 \\
\hline 4 & Penarukan & 2 & 18 & 2 & 18 & 1 & 9 & 6 & 55 & 11 & 100 \\
\hline \multirow[t]{2}{*}{5} & Banyuning & 4 & 27 & 4 & 27 & 2 & 13 & 5 & 33 & 15 & 100 \\
\hline & Jumlah & 7 & 13 & 10 & 18 & 5 & 9 & 33 & 60 & 55 & 100 \\
\hline \multicolumn{12}{|c|}{ Nonmigran } \\
\hline
\end{tabular}




\begin{tabular}{llrrrrrrrrrr}
\hline $\mathbf{1}$ & Banyuasri & 1 & 20 & 1 & 20 & 0 & 0 & 3 & 60 & 5 & 100 \\
$\mathbf{2}$ & Kampung Anyar & 3 & 33 & 3 & 33 & 1 & 11 & 2 & 22 & 9 & 100 \\
$\mathbf{3}$ & Kampung Baru & 5 & 50 & 1 & 10 & 2 & 20 & 2 & 20 & 10 & 100 \\
$\mathbf{4}$ & Penarukan & 2 & 33 & 2 & 33 & 1 & 17 & 1 & 17 & 6 & 100 \\
$\mathbf{5}$ & Banyuning & 1 & 8 & 9 & 75 & 0 & 0 & 3 & 25 & 12 & 100 \\
& Jumlah & 12 & 29 & 16 & 38 & 4 & 10 & 11 & 26 & 42 & 100 \\
\hline
\end{tabular}

Sumber: Data Primer, 2017

Keterangan:
A. Jarak antar anak berurutan antara 1-3 tahun
B. Jarak antar anak berurutan asntara 4- 6 tahun
C. Jarak antar anak 7 tahun atau $>7$ tahun
D. Jarak antar anak tidak teratur

Berdasarkan Tabel 3 dapat dilihat perbedaan pengaturan jarak antar anak yang dimiliki PUS migran dan nonmigran. Pengaturan jarak anak pada PUS migran masih tidak teratur, tertinggi pada Kelurahan Banyuning (33\%) dan terendah pada Kelurahan Kampung Baru (81\%). Hal ini memperlihatkan bahwa PUS migran masih kurang sadar akan pentingnya mengatur jarak kelahiran bagi kesehatan lbu dan anak. Sedangkan pada PUS nonmigran sudah diatur lebih baik, pada jarak 4-6 tahun per anak, tertinggi pada Kelurahan Banyuning (75\%) dan terendah pada Kelurahan Kampung Baru (10\%).
Dilihat dari jarak anak yang dimiliki PUS migran dan PUS nonmigran yang tidak teratur pada anak yang dimiliki oleh PUS migran dikarenakan kurangmya partisipasi pada penggunaan alat kontrasepsi dan belum memahami pentingnya pengetahuan tentang mengatur jarak kelahiran anak bagi kesehatan ibu juga anak tersebut. Dibandingkan dengan pengaturan jarak anak pada PUS nonmigran yang lebih baik dikarenakan wanita PUS nonmigran sudah berpartisipasi pada penggunaan alat kontrasepsi dan juga sudah memahami pentingnya pengetahuan mengatur jarak kelahiran anak bagi kesehatan ibu juga anak tersebut.

\section{Usia Kawin Pertama}

Tabel 4. Faktor usia KawinPertama yang Mempengaruhi Fertilitas Migran dan Nonmigran

\begin{tabular}{|c|c|c|c|c|c|c|c|c|}
\hline \multicolumn{9}{|c|}{ Migran } \\
\hline \multirow[t]{3}{*}{ No } & \multirow{3}{*}{$\begin{array}{l}\text { Tempat Tinggal/ } \\
\text { Kelurahan }\end{array}$} & \multirow{3}{*}{$\begin{array}{c}\text { Jumlah } \\
\text { Anak }\end{array}$} & \multicolumn{4}{|c|}{ Usia kawin } & \multicolumn{2}{|c|}{ Total } \\
\hline & & & \multicolumn{2}{|c|}{ Muda } & \multicolumn{2}{|c|}{ Dewasa } & & \\
\hline & & & $\mathbf{N}$ & $\%$ & $\mathbf{N}$ & $\%$ & $\mathbf{N}$ & $\%$ \\
\hline \multirow[t]{3}{*}{1} & Banyuasri & $1-2$ & 0 & 0 & 7 & 100 & 7 & 100 \\
\hline & & $3-4$ & 2 & 67 & 1 & 33 & 2 & 100 \\
\hline & & $5-6$ & 0 & 0 & 2 & 100 & 2 & 100 \\
\hline \multirow[t]{3}{*}{2} & Kampung Anyar & $1-2$ & 3 & 50 & 3 & 50 & 6 & 100 \\
\hline & & $3-4$ & 0 & 0 & 3 & 100 & 3 & 100 \\
\hline & & $5-6$ & 0 & 0 & 2 & 100 & 2 & 100 \\
\hline \multirow[t]{3}{*}{3} & Kampung baru & $1-2$ & 1 & 25 & 3 & 75 & 4 & 100 \\
\hline & & $3-4$ & 2 & 40 & 3 & 60 & 5 & 100 \\
\hline & & $5-6$ & 0 & 0 & 3 & 100 & 3 & 100 \\
\hline \multirow[t]{3}{*}{4} & Penarukan & $1-2$ & 1 & 50 & 1 & 50 & 2 & 100 \\
\hline & & $3-4$ & 1 & 17 & 5 & 83 & 6 & 100 \\
\hline & & $5-6$ & 1 & 33 & 2 & 67 & 3 & 100 \\
\hline \multirow[t]{4}{*}{5} & Banyuning & $1-2$ & 2 & 50 & 2 & 50 & 4 & 100 \\
\hline & & $3-4$ & 3 & 37 & 5 & 63 & 8 & 100 \\
\hline & & $5-6$ & 2 & 50 & 2 & 50 & 4 & 100 \\
\hline & Jumlah & & 18 & 29 & 44 & 71 & 62 & 100 \\
\hline \multicolumn{9}{|c|}{ Nonmigran } \\
\hline \multirow[t]{3}{*}{1} & Banyuasri & $1-2$ & 3 & 50 & 3 & 50 & 6 & 100 \\
\hline & & $3-4$ & 1 & 25 & 3 & 75 & 4 & 100 \\
\hline & & $5-6$ & 0 & 0 & 0 & 0 & 0 & 100 \\
\hline \multirow[t]{3}{*}{2} & Kampung Anyar & $1-2$ & 3 & 33 & 6 & 67 & 9 & 100 \\
\hline & & $3-4$ & 1 & 25 & 3 & 75 & 4 & 100 \\
\hline & & $5-6$ & 0 & 0 & 0 & 0 & 0 & 100 \\
\hline
\end{tabular}




\begin{tabular}{|c|c|c|c|c|c|c|c|c|}
\hline \multirow[t]{3}{*}{3} & Kampung Baru & $1-2$ & 5 & 63 & 3 & 37 & 8 & 100 \\
\hline & & $3-4$ & 0 & 0 & 5 & 100 & 5 & 100 \\
\hline & & $5-6$ & 0 & 0 & 0 & 0 & 0 & 100 \\
\hline \multirow[t]{3}{*}{4} & Penarukan & $1-2$ & 2 & 33 & 4 & 67 & 6 & 100 \\
\hline & & $3-4$ & 0 & 0 & 3 & 100 & 3 & 100 \\
\hline & & $5-6$ & 0 & 0 & 0 & 0 & 0 & 100 \\
\hline \multirow[t]{4}{*}{5} & Banyuning & $1-2$ & 2 & 50 & 2 & 50 & 4 & 100 \\
\hline & & $3-4$ & 3 & 30 & 7 & 70 & 10 & 100 \\
\hline & & $5-6$ & 0 & 0 & 0 & 0 & 0 & 100 \\
\hline & Jumlah & & 20 & 34 & 39 & 66 & 59 & 100 \\
\hline
\end{tabular}

Sumber: Data Primer, 2017

Usia kawin pertama dibedakan menjadi 2 yaitu umur muda ( $\leq 20$ tahun) dan umur dewasa (>20 tahun). Berdasarkan Tabel 4 tidak terdapat perbedaan yang signifikan antara faktor usia kawin pertama pada wanita PUS migran dan wanita PUS nonmigran. Hasil penelitian juga menunjukkan bahwa tidak ada hubungan antara UK I dengan jumlah yang dimiliki, baik migran maupun nonmigran. Hal tersebut terbukti dari jumlah anak yang dimiliki 16 orang, masing-masing terdapat pada pasangan yang kawin baik di usia muda maupun dewasa.

Hasil penelitian juga menunjukkan bahwa pada PUS migran secara umum jumlah anak yang terbesar dan terendah bervariasi di setiap wilayahnya. Namun pada 3 wilayah (Kelurahan Banyuasri, Kelurahan Kampung Anyar, dan Kelurahan Kampung Baru) jumlah anak terbesar terdapat di jumlah anak 5-6 orang pada UK I dewasa dan jumlah anak terendah terdapat di jumlah anak 5-6 orang pada UK I muda, serta Kelurahan Penarukan dan Kelurahan Banyuning jumlah anak terbesar terdapat pada jumlah anak 3-4 anak pada UK I dewasa dan jumlah anak terendah terdapat pada jumlah anak 3-4 orang pada UK I muda. Sedangkan pada PUS nonmigran jumlah anak pada 5 wilayah terbesar pada jumlah anak 3-4 orang pada UK I dewasa dan jumlah anak terendah adalah pada jumlah anak 5-6 pada UK I muda dan dewasa.

Kesamaan rata-rata usia kawin penduduk migran dan nonmigran di Kota Singaraja dapat disebabkan oleh pemahaman akan resiko-resiko yang dapat terjadi jika menikah di usia muda atau belia yang sudah lebih baik

Dibandingkan dengan penelitian sebelumnya, penelitian ini memiliki perbedaan dengan penelitian yang dilakukan oleh Muhammad Nasir pada tahun 2012. Hasil penelitian menunjukan bahwa faktor usia kawin pertama merupakan faktor yang mempengaruhi tingginya tingkat fertilitas.

Dibandingkan dengan penelitian sebelumnya, penelitian ini memiliki perbedaan dengan penelitian yang dilakukan oleh Sri Yuniarti pada tahun 2011. Hasil penelitian menunjukan bahwa faktor usia kawin pertama merupakan faktor yang mempengaruhi tingginya tingkat fertilitas.

\section{Pendidikan}

Tabel 5. Faktor Pendidikan yang Mempengaruhi Fertilitas Migran dan Nonmigran

\begin{tabular}{|c|c|c|c|c|c|c|c|c|c|c|c|c|}
\hline \multicolumn{13}{|c|}{ Migran } \\
\hline \multirow[t]{3}{*}{ No } & \multirow{3}{*}{$\begin{array}{c}\text { Tempat } \\
\text { Tinggal/ } \\
\text { Kelurahan }\end{array}$} & \multirow{3}{*}{$\begin{array}{c}\text { Jumlah } \\
\text { Anak }\end{array}$} & \multicolumn{8}{|c|}{ Jenjang Pendidikan } & \multicolumn{2}{|c|}{ Total } \\
\hline & & & \multicolumn{2}{|c|}{1} & \multicolumn{2}{|c|}{2} & \multicolumn{2}{|c|}{3} & \multicolumn{2}{|c|}{4} & \\
\hline & & & $\mathbf{N}$ & $\%$ & $\mathbf{N}$ & $\%$ & $\mathbf{N}$ & $\%$ & $\mathbf{N}$ & $\%$ & $\mathbf{N}$ & $\%$ \\
\hline \multirow[t]{3}{*}{1} & Banyuasri & $1-2$ & 2 & 29 & 1 & 14 & 1 & 14 & 3 & 43 & 7 & 100 \\
\hline & & 3-4 & 0 & 0 & 0 & 0 & 3 & 100 & 0 & 0 & 3 & 100 \\
\hline & & $5-6$ & 0 & 0 & 0 & 0 & 2 & 100 & 0 & 0 & 2 & 100 \\
\hline \multirow[t]{3}{*}{2} & Kampung Anyar & $1-2$ & 0 & 0 & 0 & 0 & 3 & 100 & 0 & 0 & 3 & 100 \\
\hline & & $3-4$ & 0 & 0 & 1 & 17 & 4 & 66 & 1 & 17 & 5 & 100 \\
\hline & & $5-6$ & 0 & 0 & 0 & 0 & 2 & 100 & 0 & 0 & 2 & 100 \\
\hline \multirow[t]{3}{*}{3} & Kampung baru & $1-2$ & 0 & 0 & 1 & 25 & 2 & 50 & 1 & 25 & 4 & 100 \\
\hline & & 3-4 & 2 & 40 & 0 & 0 & 3 & 60 & 0 & 0 & 5 & 100 \\
\hline & & $5-6$ & 0 & 0 & 0 & 0 & 2 & 67 & 1 & 33 & 3 & 100 \\
\hline \multirow[t]{2}{*}{4} & Penarukan & $1-2$ & 0 & 0 & 0 & 0 & 1 & 50 & 1 & 50 & 2 & 100 \\
\hline & & $3-4$ & 0 & 0 & 0 & 0 & 2 & 33 & 4 & 67 & 6 & 100 \\
\hline
\end{tabular}




\begin{tabular}{|c|c|c|c|c|c|c|c|c|c|c|c|c|}
\hline & & $5-6$ & 0 & 0 & 0 & 0 & 1 & 33 & 2 & 67 & 3 & 100 \\
\hline \multirow[t]{4}{*}{5} & Banyuning & $1-2$ & 0 & 0 & 1 & 25 & 1 & 25 & 2 & 50 & 4 & 100 \\
\hline & & $3-4$ & 1 & 12.5 & 1 & 12.5 & 5 & 62.5 & 1 & 12.5 & 8 & 100 \\
\hline & & $5-6$ & 0 & 0 & 1 & 25 & 2 & 50 & 1 & 25 & 4 & 100 \\
\hline & Jumlah & & 5 & 8 & 6 & 10 & 34 & 55 & 17 & 27 & 62 & 100 \\
\hline \multicolumn{13}{|c|}{ Nonmigran } \\
\hline & Banyuasri & $1-2$ & 0 & 0 & 0 & 0 & 2 & 33 & 4 & 67 & 6 & 100 \\
\hline \multirow[t]{2}{*}{1} & & $3-4$ & 1 & 25 & 1 & 25 & 1 & 25 & 1 & 25 & 4 & 100 \\
\hline & & $5-6$ & 0 & 0 & 0 & 0 & 0 & 0 & 0 & 0 & 0 & 100 \\
\hline \multirow[t]{3}{*}{2} & Kampung Anyar & $1-2$ & 1 & 11 & 1 & 11 & 4 & 45 & 3 & 33 & 9 & 100 \\
\hline & & $3-4$ & 2 & 50 & 0 & 0 & 2 & 50 & 0 & 0 & 4 & 100 \\
\hline & & $5-6$ & 0 & 0 & 0 & 0 & 0 & 0 & 0 & 0 & 0 & 100 \\
\hline \multirow[t]{3}{*}{3} & Kampung Baru & $1-2$ & 1 & 12.5 & 1 & 12.5 & 2 & 25 & 4 & 50 & 8 & 100 \\
\hline & & $3-4$ & 0 & 0 & 0 & 0 & 0 & 0 & 5 & 100 & 5 & 100 \\
\hline & & $5-6$ & 0 & 0 & 0 & 0 & 0 & 0 & 0 & 0 & 0 & 100 \\
\hline \multirow[t]{3}{*}{4} & Penarukan & $1-2$ & 0 & 0 & 1 & 17 & 3 & 50 & 2 & 33 & 6 & 100 \\
\hline & & $3-4$ & 0 & 0 & 0 & 0 & 1 & 33 & 2 & 67 & 3 & 100 \\
\hline & & $5-6$ & 0 & 0 & 0 & 0 & 0 & 0 & 0 & 0 & 0 & 100 \\
\hline \multirow[t]{4}{*}{5} & Banyuning & $1-2$ & 0 & 0 & 0 & 0 & 2 & 50 & 2 & 50 & 4 & 100 \\
\hline & & $3-4$ & 1 & 10 & 1 & 10 & 5 & 50 & 3 & 30 & 10 & 100 \\
\hline & & $5-6$ & 0 & 0 & 0 & 0 & 0 & 0 & 0 & 0 & 0 & 100 \\
\hline & Jumlah & & 6 & 10 & 5 & 9 & 22 & 37 & 26 & 44 & 59 & 100 \\
\hline
\end{tabular}

Sumber: Data Primer, 2017

Keterangan:

1. Tamat Jenjang Pendidikan Dasar

2. Tamat Pendidikan Sekolah Menengah Pertama

3. Tamat Jenjang Pendidikan Sekolah Menengah Atas

4. Tamat Jenjang Perguruan Tinggi

Hasil penelitian menunjukkan bahwa tidak ada hubungan antara pendidikan dengan jumlah yang dimiliki, baik migran maupun nonmigran. Hal tersebut terbukti dari jumlah anak yang dimiliki 1-6 orang, masing-masing terdapat pada wanita PUS baik migran maupun nonmigran yang tersebar di masing-masing tingkatan pendidikan terakhir yang ditamatkan.

Hasil penelitian menunjukkan bahwa pada PUS migran secara umum jumlah anak yang terbesar dan terendah bervariasi di setiap wilayahnya. Namun pada 3 wilayah (Kelurahan Banyuasri, Kelurahan Kampung Anyar, dan Kelurahan Kampung Baru) jumlah anak terbesar terdapat di jumlah anak 5-6 orang dengan pendidikan terakhir yang ditamatkan Pendidikan Sekolah Menengah Atas (SMA) dan jumlah anak terendah terdapat di jumlah anak 1-2,34, serta 5-6 orang dengan pendidikan terakhir yang ditamatkan Sekolah Dasar (SD), Sekolah Menengah Pertama (SMP), dan Perguruan Tinggi, serta Kelurahan Penarukan dan Kelurahan Banyuning jumlah anak terbesar terdapat pada jumlah anak 3-4 anak dengan pendidikan terakhir yang ditamatkan Sekolah Menengah Atas dan Perguruan Tinggi. Jumlah anak terendah terdapat pada jumlah anak 1-2,
3-4, dan 5-6 orang dengan pendidikan terakhir yang ditamatkan Sekolah Dasar (SD) dan Sekolah Menengah Pertama (SMP). Sedangkan pada PUS nonmigran jumlah anak pada 5 wilayah terbesar pada jumlah anak 1-2 orang dan 3-4 orang dengan pendidikan terakhir yang ditamatkan Sekolah Menengah Atas (SMA) (Kelurahan Penarukan dan Kelurahan Kampung Anyar) dan Perguruan Tinggi. Jumlah anak terendah adalah pada jumlah anak 5-6 orang dengan pendidikan terakhir yang ditamatkan Sekolah Dasar (SD) dan Sekolah Menengah Pertama (SMP) Sekolah Menengah Atas (SMA) dan Perguruan Tinggi.

Wanita PUS migran berpeluang lebih besar memiliki jumlah anak yang banyak karena setelah menamatkan pendidikan terdapat wanita PUS migran yang langsung memutuskan menikah, hal ini bertolak belakang dengan Usia Kawin I yang dewasa. Menikah pada usia dewasa, tetapi pemahaman tentang KB belum sebaik penduduk nonmigran. $\mathrm{Hal}$ ini berkaitan dengan tingkat pendidikan yang di tamatkan, semakin tinggi pendidikan, semakin besar peluang untuk menerima inovasi yang dalam hal ini adalah KB, khususnya berkaitan dengan jumlah dan jarak 
kelahiran yang sangat terkait dengan sosial ekonomi.

Dibandingkan dengan penelitian sebelumnya, penelitian ini memiliki perbedaan dengan penelitian yang dilakukan oleh Muhammad Nasir pada tahun 2012. Hasil penelitian menunjukan bahwa faktor pendidikan istri mempengaruhi fertilitas yang dianalisis menggunakan resgresi logistik.
Dibandingkan dengan penelitian sebelumnya, penelitian ini memiliki perbedaan dengan penelitian yang dilakukan oleh Sri Yuniarti pada tahun 2011. Hasil penelitian menunjukan bahwa pendidikan merupakan faktor yang mempengaruhi tingginya tingkat fertilitas.

\section{Pendapatan}

Tabel 6 Faktor Pendapatan yang Mempengaruhi Fertilitas Migran dan Nonmigran

\begin{tabular}{|c|c|c|c|c|c|c|c|c|c|c|}
\hline \multicolumn{11}{|c|}{ Migran } \\
\hline \multirow[t]{2}{*}{ No } & \multirow{2}{*}{$\begin{array}{c}\text { Tempat } \\
\text { Tinggal/ } \\
\text { Kelurahan }\end{array}$} & \multirow[t]{2}{*}{$\begin{array}{c}\text { Jumlah } \\
\text { Anak }\end{array}$} & \multicolumn{2}{|c|}{ Rendah } & \multicolumn{2}{|c|}{$\begin{array}{l}\text { Pendapatan } \\
\text { Sedang }\end{array}$} & \multicolumn{2}{|c|}{ Tinggi } & \multicolumn{2}{|c|}{ Total } \\
\hline & & & $\mathbf{N}$ & $\%$ & $\mathbf{N}$ & $\%$ & $\mathbf{N}$ & $\%$ & $\mathbf{N}$ & $\%$ \\
\hline \multirow[t]{3}{*}{1} & Banyuasri & $1-2$ & 4 & 57 & 1 & 14 & 2 & 29 & 7 & 100 \\
\hline & & $3-4$ & 3 & 100 & 0 & 0 & 0 & 0 & 3 & 100 \\
\hline & & $5-6$ & 2 & 100 & 0 & 0 & 0 & 0 & 2 & 100 \\
\hline \multirow[t]{3}{*}{2} & Kampung & $1-2$ & 3 & 100 & 0 & 0 & 0 & 0 & 3 & 100 \\
\hline & Anyar & $3-4$ & 6 & 100 & 0 & 0 & 0 & 0 & 6 & 100 \\
\hline & & $5-6$ & 2 & 100 & 0 & 0 & 0 & 0 & 2 & 100 \\
\hline \multirow[t]{3}{*}{3} & Kampung baru & $1-2$ & 4 & 100 & 0 & 0 & 0 & 0 & 4 & 100 \\
\hline & & $3-4$ & 5 & 100 & 0 & 0 & 0 & 0 & 5 & 100 \\
\hline & & $5-6$ & 3 & 100 & 0 & 0 & 0 & 0 & 3 & 100 \\
\hline \multirow[t]{3}{*}{4} & Penarukan & $1-2$ & 1 & 50 & 0 & 0 & 1 & 50 & 2 & 100 \\
\hline & & $3-4$ & 5 & 83 & 0 & 0 & 1 & 17 & 6 & 100 \\
\hline & & $5-6$ & 1 & 33 & 0 & 0 & 2 & 67 & 3 & 100 \\
\hline \multirow[t]{4}{*}{5} & Banyuning & $1-2$ & 4 & 100 & 0 & 0 & 0 & 0 & 4 & 100 \\
\hline & & $3-4$ & 7 & 87.5 & 1 & 12.5 & 0 & 0 & 8 & 100 \\
\hline & & $5-6$ & 1 & 25 & 2 & 50 & 1 & 25 & 4 & 100 \\
\hline & Jumlah & & 51 & 82 & 4 & 7 & 7 & 11 & 62 & 100 \\
\hline \multicolumn{11}{|c|}{ Nonmigran } \\
\hline \multirow[t]{3}{*}{1} & Banyuasri & $1-2$ & 3 & 50 & 0 & 0 & 3 & 50 & 6 & 100 \\
\hline & & $3-4$ & 4 & 100 & 0 & 0 & 0 & 0 & 4 & 100 \\
\hline & & $5-6$ & 0 & 0 & 0 & 0 & 0 & 0 & 0 & 100 \\
\hline \multirow[t]{3}{*}{2} & Kampung & $1-2$ & 9 & 100 & 0 & 0 & 0 & 0 & 9 & 100 \\
\hline & Anyar & $3-4$ & 4 & 100 & 0 & 0 & 0 & 0 & 4 & 100 \\
\hline & & $5-6$ & 0 & 0 & 0 & 0 & 0 & 0 & 0 & 100 \\
\hline \multirow[t]{3}{*}{3} & Kampung Baru & $1-2$ & 8 & 100 & 0 & 0 & 0 & 0 & 8 & 100 \\
\hline & & $3-4$ & 5 & 100 & 0 & 0 & 0 & 0 & 5 & 100 \\
\hline & & $5-6$ & 0 & 0 & 0 & 0 & 0 & 0 & 0 & 100 \\
\hline \multirow[t]{3}{*}{4} & Penarukan & $1-2$ & 4 & 67 & 0 & 0 & 2 & 33 & 6 & 100 \\
\hline & & $3-4$ & 2 & 67 & 0 & 0 & 1 & 33 & 3 & 100 \\
\hline & & $5-6$ & 0 & 0 & 0 & 0 & 0 & 0 & 0 & 100 \\
\hline \multirow[t]{4}{*}{5} & Banyuning & $1-2$ & 2 & 50 & 0 & 0 & 2 & 50 & 4 & 100 \\
\hline & & $3-4$ & 7 & 70 & 1 & 10 & 2 & 20 & 10 & 100 \\
\hline & & $5-6$ & 0 & 0 & 0 & 0 & 0 & 0 & 0 & 100 \\
\hline & Jumlah & & 48 & 81 & 1 & 2 & 10 & 17 & 59 & 100 \\
\hline
\end{tabular}

Sumber: Data Primer, 2017

Keterangan:
1. Rendah
: Rp. $900.000-$ Rp. 2.100 .000
2. Sedang
:Rp. 2.100.001 - Rp. 3.300.001
3. Tinggi
: Rp. 3.300 .002 - Rp. 4.500 .002

Hasil penelitian menunjukkan bahwa tidak ada hubungan antara pendapatan dengan jumlah yang dimiliki, baik migran maupun nonmigran. Hal tersebut terbukti dari jumlah anak yang dimiliki 1-6 orang, masing-masing terdapat pada pasangan yang kawin pada tingkat pendapatan yang rendah.

Hasil penelitian menunjukkan bahwa pada PUS migran jumlah anak yang terbesar terdapat di jumlah anak 1 2 , 3-4, dan 5-6 orang dengan 
pendapatan rendah (Rp. $900.000-\mathrm{Rp}$. 2.100.000) dan jumlah anak terendah terdapat di jumlah anak 1-2,3-4, serta 56 orang dengan pendapatan sedang (Rp. 2.100.001 - Rp. 3.300.001) dan tinggi (Rp. 3.300.002 - Rp. 4.500.002). Sedangkan pada PUS nonmigran jumlah anak pada 5 wilayah terbesar pada jumlah anak 1-2 orang dan 3-4 orang dengan pendapatan rendah (Rp. 900.000 - Rp. 2.100.000). Jumlah anak terendah adalah pada jumlah anak 5-6 orang dengan pendapatan sedang (Rp. 2.100.001 - Rp. 3.300.001) dan tinggi (Rp. 3.300.002 - Rp. 4.500.002).

Rendahnya pendaptan yang dimiliki oleh wanita PUS migran dan nonmigran disebabkan sebagian besar wanita PUS memiliki pekerjaan dan mendapat penghasilan setelah mereka menikah. Sementara wanita PUS nonmigran memilih menikah dan mempunyai anak karena telah memiliki pekerjaan yang layak dan sudah memiliki penghasilan sendiri yang dirasa cukup sebagai bekal mereka berumah tangga. Sehingga pendapatan tidak mempengaruhi fertilitas migran di Kota Singaraja.

Dibandingkan dengan penelitian sebelumnya, penelitian ini memiliki perbedaan dengan penelitian yang dilakukan oleh Muhammad Nasir pada tahun 2012. Hasil penelitian menunjukan bahwa faktor pendapatan merupakan faktor yang mempengaruhi tingginya tingkat fertilitas.

Dibandingkan dengan penelitian sebelumnya, penelitian ini memiliki perbedaan dengan penelitian yang dilakukan oleh Sri Yuniarti pada tahun 2011. Hasil penelitian menunjukan 2) Hasil Uji Normalitas Data

Pengujian normalitas data dilakukan untuk menyakikan bahwa sampel berasal dari populasi yang berdistribusi normal. Pada penelitian ini, untuk mengetahui apakah sebaran data jumlah anak PUS migran dan nonmigran di Kota Singaraja berdistribusi normal digunakan uji kolmogorov-smirnov satu sampel. Digunakannya Kolmogorov- bahwa faktor pendapatan merupakan faktor yang mempengaruhi tingginya tingkat fertilitas.

Perbedaan Fertilitas Migran dan Nonmigran di Kota Singaraja

1) Uji Homogenitas Data Pengujian

homogenitas dilakukan setelah pengujian normalitas data sebagai salah satu syarat untuk dapat meguji data dengan uji t. Pengujian homogenitas data dari dua kelompok dapat dikatakan berbeda atau tidak sama jika taraf signifikansinya kurang dari 0,05 dan jika taraf signifikansinya lebih dari 0,05 maka data dari dua kelompok sampel adalah sama. Uji homogenitas dalam penelitian ini dilakukan menggunakan SPSS 16 for windows.

\begin{tabular}{ccc}
\multicolumn{2}{c}{ Berdasarkan } & hasil uji \\
homogenitas dengan uji Levene & \\
menunjukkan bahwa koefisien $F$
\end{tabular} menunjukkan bahwa koefisien sebesar 0,168 . Dengan nilai signifikansi lebih besar dari 0,05 maka data dari kedua sampel adalah sama, maka uji $\mathrm{t}$ yang digunakan adalah uji sampel independen yang homogen. Data hasil pengujian menggunakan SPSS 16 for windows dapat dilihat pada Tabel 7 berikut.

Tabel 7 Pengujian Homogenitas Data

Levene's Test of Equality of Error Variance

\begin{tabular}{lrrr}
\hline F & df1 & df2 & \multicolumn{1}{l}{ Sig. } \\
$\mathbf{1 . 9 2 5}$ & 1 & 121 & .168 \\
\hline
\end{tabular}

smirnov satu sampel dikarenakan distribusi nilai sampel yang digunakan sangat kecil. Jika nilai Signifikan besar dari 0,05 (taraf kesalahan 5\%) maka data berdistribusi normal. Hasil hitung Uji Normalitas Kolmogorov-smirnov pada data jumlah anak PUS migran dan nonmigran. Untuk lebih jelas dapat diperhatikan tabel 8 berikut. 
Tabel 8 Uji Normalitas Data Migran dan Nonmigran di Kota Singraja

\begin{tabular}{llrr}
\hline $\mathbf{N}$ & & MIGRAN & NONMIGRAN \\
\cline { 2 - 4 } $\begin{array}{l}\text { Normal } \\
\text { Parameters }\end{array}$ & Mean & 62 & 61 \\
& & 3.2097 & 2.2623 \\
Most & Std. Deviation & 1.34453 & 1.12401 \\
Extreme & Absolute & .159 & .170 \\
Differences & & & \\
& Positive & .159 & .166 \\
Kolmogorov- & Negative & -.134 & -.170 \\
Smirnov Z & & 1.250 & 1.331 \\
$\begin{array}{l}\text { Asymp. Sig. } \\
\text { (2-tailed) }\end{array}$ & & .088 & .058 \\
\hline
\end{tabular}

Berdasarkan Tabel 8 memperlihatkan hasil Signifikansi untuk data migran dan nonmigran besar dari 0,05 (taraf kesalahan $5 \%$ ), sehingga sebaran data migran dan nonmigran berdistribusi normal. Analisis data ini dilakukan dengan program SPSS 16 for windows.

3) Hasil Uji Beda fertilitas Migran dan Nonmigran di kota Singaraja
Perbedaan Fertilitas ini di analisis dengan menggunakan analisis t-test.ttest digunakan untuk menguji signifikansi beda rata-rata dua kelompok. Tes ini digunakan untuk menganalisis perbedaan dua sampel. Berdasarkan hasil penelitian, perbedaan fertilitas migran dan nonmigran di Kota Singaraja dapat disajikan pada Tabel 10 sebai berikut.

Tabel 10 Uji Beda Fertilitas Migran dan Nonmigran di Kota Singaraja

\begin{tabular}{|c|c|c|c|c|c|c|c|c|c|}
\hline & \multicolumn{2}{|c|}{$\begin{array}{l}\text { Levene's } \\
\text { Test for } \\
\text { Equality of } \\
\text { Variances }\end{array}$} & \multicolumn{5}{|c|}{ t-test for Equality of Means } & \multicolumn{2}{|c|}{$\begin{array}{c}95 \% \\
\text { Confidence } \\
\text { Interval of the } \\
\text { Difference }\end{array}$} \\
\hline & $\bar{F}$ & Sig. & $\bar{T}$ & Df & $\begin{array}{c}\text { Sig. } \\
(2- \\
\text { tailed } \\
)\end{array}$ & $\begin{array}{c}\text { Mean } \\
\text { Differe } \\
\text { nce }\end{array}$ & $\begin{array}{c}\text { Std. } \\
\text { Error } \\
\text { Differen } \\
\text { ce } \\
\end{array}$ & Lower & Upper \\
\hline $\begin{array}{l}\text { Equal } \\
\text { variances } \\
\text { assumed }\end{array}$ & 1.925 & .168 & 4.236 & 121 & .000 & $\begin{array}{r}.9473 \\
8\end{array}$ & .22364 & $\begin{array}{r}.5046 \\
3\end{array}$ & $\begin{array}{r}1.390 \\
13\end{array}$ \\
\hline $\begin{array}{l}\text { Equal } \\
\text { variances } \\
\text { not } \\
\text { assumed }\end{array}$ & & & 4.242 & 117.939 & .000 & $\begin{array}{r}.9473 \\
8\end{array}$ & .22331 & $\begin{array}{r}.5051 \\
6\end{array}$ & $\begin{array}{r}1.389 \\
61\end{array}$ \\
\hline
\end{tabular}

Berdasarkan tabel 10, dapat diketahui bahwa terdapat perbedaan fertilitas antara wanita PUS migran dan nonmigran. Hal tersebut dapat dilihat dari t hitung sebesar 4,236 dan t tabel 1,970. Artinya $t$ hitung $>t$ tabel denga nilai signifikansi (sig.(2-tailed)) $0,000<$ 0,05 . Berdasarkan hasil penelitian menyatakan bahwa hipotesis tersebut terbukti, karena terdapat perbedaan fertilitas antara penduduk migran dan nonmigran. PUS migran masih ada yang memilki anak 5 sampai 6 anak sedangkan penduduk nonmigran sudah tidak memiliki anak 5 sampai 6 orang anak 


\section{SIMPULAN DAN SARAN}

Karakteristik fertilitas migran dan nonmigran di Kota Singaraja dilihat dari jumlah anak dan jarak kelahiran yang dimiliki wanita PUS adalah berbeda. Rata-rata jumlah anak yang dimiliki migran berkisar antara 3-4 anak bahkan terdapat jumlah anak 5-6 anak, dengan jarak kelahiran antar anak yang tidak teratur. Sementara rata-rata jumlah anak yang dimiliki wanita PUS nonmigran adalah berkisar 1-2 anak dengan jarak antar anak yang lebih teratur, yaitu antara 4-6 tahun.

Faktor usia kawin pertama, pendapatan dan pendidikan merupakan faktor-faktor yang tidak mempengaruhi fertilitas migran dan nonmigran di Kota Singarja.

Terdapat perbedaan secara signifikan antara fertilitas migran dan nonmigran di Kota Singaraja (t-hitung $4,236>$ t-tabel 1,970 , pada taraf signifikan $0,05 \%$ ).

Memperhaikan penduduk wanita migran yang memiliki jumlah anak ratarata 3-4 anak dan bahkan masih ada yang memiliki anak dengan jumlah 5-6

\section{DAFTAR PUSTAKA}

Astawa, Ida Bagus Made, 2010. Demografi Teknik untuk Lembaga Pendidikan Tenaga Kependidikan (LPTK). Buku Ajar (tidak diterbitkan). Singaraja: Undiksha.

Nasir, Muhammad. 2012. Analisis Faktor-Faktor Ekonomi dan Sosial yang Mempengaruhi Fertilitas dei Provinsi Aceh. Jurnal Ekonomika Indonesia, Vol.1, No. 1 (hlm. 7887). Lhokseumawe. Poloteknik Negri Lhokseumawe.

Rahmadewi, Leli Asih. 2011. Tingkat Fertilitas di Provinsi Nusa Tenggara Timur dan Yogyakarta. Jurnal Kesehatan Masyarakat Nasional, Vol.6, No. 1 (hlm. 117125). Jakarta Timur. Puslitbang Kependudukan BKKBN. dengan jarak yang masih tidak teratur pada migran di Kota Singaraja diharapkan dapat merencanakan jumlah anak yang akan dimiliki dan dapat mengatur jarak kelahiran antar anak dengan baik, misalnya menggunakan alat kontrasepsi, baik berupa Pil maupun suntikan.

Perlu dilakukan penelitian yang lebih luas dengan sampel yang besar untuk melihat bagaimana variasi fertilitas migran dan nonmigran di Kota Singaraja sehingga dapat mengungkap fenomena fertilitas migran dan nonmigran secara lebih luas.

Penelitian ini masih memiliki kelemahan karena belum memperhitungkan faktor UK I, faktor pendidikan, dan faktor pendapatan sebagai variable independent untuk dikaitkan dengan variable dependent (fertilitas), hanya menggunakan tabel silang (crosstabs), sehingga penelitian selanjutnya diharapkan agar menggunakan uji statistik, agar hasilnya lebih pasti.

Sudibia, I Ketut. 2013. Studi Komparatif Fertilitas Penduduk antara Migran dan Nonmigran di Provinsi Bali. Jurnal Kependudukan \& Pengembangan Sumber Daya MAnusia, Vol.9, No. 2 (hlm. 7788). Desember 2013. Denpasar. Universitas Udayana.

Sudjinggo. 1988. Teknik Pengukuran Demografi Jilid $I$. Jakarta: P2LPTK/Ketua UPBT.

Yuniarti, Sri; H Sukandar; H Susiarno., 2013. Analisis Faktor yang Berhubungan dengan Fertilitas: Suatu Kajian Literatur, Universitas Padjajaran, Bandung. Pustaka.unpad.ac.id (diakses 04 Desember 2016). 